\title{
COSMO-SkyMed Synthetic Aperture Radar data to observe the Deepwater Horizon oil spill
}

\author{
Ferdinando Nunziata ${ }^{1, *}$ (iD), Andrea Buono ${ }^{1, *}$ (iD) and Maurizio Migliaccio 1,* (D) \\ 1 Università degli Studi di Napoli Parthenope, Dipartimento di Ingegneria; \\ nunziata,andrea.buono,migliaccio@uniparthenope.it \\ * Correspondence: \{nunziata,andrea.buono,migliaccio\}@uniparthenope.it; Tel.: +39-081-547-6768
}

\begin{abstract}
Oil spills are adverse events that may be very harmful to ecosystems and food chain. In particular, large sea oil spills are very dramatic occurrence often affecting sea and coastal areas. Therefore the sustainability of oil rig infrastructures and oil transportation via oil tankers are linked to law enforcement based on proper monitoring techniques which are also fundamental to mitigate the impact of such pollution. Within this context, in this study a meaningful showcase is analyzed using remotely sensed measurements collected by the Synthetic Aperture Radar (SAR) operated by the COSMO-SkyMed (CSK) constellation.

The showcase presented refers to the Deepwater Horizon (DWH) oil incident that occurred in the Gulf of Mexico in 2010. It is one of the world's largest incidental oil pollution event that affected a sea area larger than $10,000 \mathrm{~km}^{2}$. In this study we exploit, for the first time, dual co-polarization SAR data collected by the Italian CSK X-band SAR constellation showing the key benefits of HH-VV SAR measurements in observing such a huge oil pollution event, especially in terms of the very dense revisit time offered by the CSK constellation.
\end{abstract}

Keywords: Sea, remote sensing, oil pollution

\section{Introduction}

Oceans, seas and all the marine resources are essential to human well-being and social and economic development [1]. Oceans provide livelihoods, subsistence and benefits from fisheries, tourism and many other sectors, also helping in regulating the global ecosystem by absorbing heat and carbon dioxide from the atmosphere. However, oceans and coastal areas are severely susceptible to environmental degradation, overfishing, climate change, biodiversity loss and pollution [2]. In particular, pollutants significantly threat coastal regions and, since river basins, marine ecosystems and the atmosphere belong all together to the same hydrological systems, its effects are often found at far distance by the polluting source. According to the 2015 "Transboundary Waters Assessment Programme" global comparative assessment, the Gulf of Mexico is one of the five largest marine ecosystems mostly at risk of pollution and eutrophication. Hence, its preservation and sustainable management are key points to be achieved in the 2030 Agenda [3]. One of the goals mentioned in the sustainable development report of 2016 explicitly states "conserve and sustainably use the oceans, seas and marine resources for sustainable development" is of primary importance [4].

Sea oil spills are the most noticeable forms of damage to the marine environment. Oil at sea comes from oil tanker or oil rig disasters, but also - and primarily — from diffuse sources, such as leaks during oil extraction, illegal tank-cleaning operations at sea, or discharges into the rivers which are then carried into the sea. Generally speaking, two classes of sea oil spill may occur, large oil spills and small oil spills. The size and duration of the spill, its chemical makeup and the marine environment are key factors to evaluate the short- and long-term ecological consequences of the spillage. While macro oil spills are well-known in general terms, the correct monitoring of the time evolving processes and the precise knowledge of the marine and coastal area affected is crucial. Micro oil spills are usually much more difficult to be monitored by patrol coast guard ships and airplanes, since they represent 
small-size events that may occurr in a large areas.

Although proper monitoring is only the first part of a challenging scientific and operational processing chain it is important to be properly made [5]. In fact, although any macro oil spill has its unique characteristics, the logic processing chain is based on some key functional tools: monitoring, forecasting and vulnerability assessment. It must be noted that many uncertainties still remain especially in forecasting of an oil spill because of meteo-marine conditions and aging that make oil forecasting a complex process that cannot be standardized in a simple way. Hence, it is important to provide to the forecast modeler the best available information in terms of sea oil coverage and possibly sea oil type. Sea oil type has a direct impact on forecasting since when oil has a predominant component that is volatile the polluting contamination process is very different with respect to the case where heavy damping oil is predominant. Generally speaking, in order to mitigate the adverse effects of a sea oil spill, it is a paramount importance to monitor the event and to provide the best information to the operational people to support remediation actions and dispatch proper bulletin to fishermen and population [6].

With reference to oil tanker security, especially after the Prestige incident in 2002, the use of double-hull tankers was meant as the primary source to limit the risk of incidents. Unfortunately, the recent Sanchi incident in 2018 demonstrated that this ship construction technology does not lead to zero risk. On the other side, oil rigs are more and more environmental risky as they move to deep and ultra-deep sea. The reference incident is the Deepwater Horizon (DWH) incident that occurred in 2010 in the Gulf of Mexico $[7,8]$. The oil spill industry sustainability is based on the increasing and increasing sea oil spill remediation capability and this is also based on the quality of the monitoring capability.

In this framework, this study focuses on the benefit of satellite day and night fine spatial-resolution Synthetic Aperture Radar (SAR) monitoring during the DWH incident. In fact, among the various remote sensing tools, SAR could effectively address the user needs in case of such huge incidental polluting events in terms of:

- area covered;

- continuous and almost near real-time operability.

SAR imaging characteristics provide several extra-benefits if compared to optical remote sensing, even though the latter is extensively used to retrieve rough estimations of oil thickness and chemical properties. However, optical measurements are severely affected by weather conditions and, furthermore, response efforts as the use of chemical dispersants, may alter oil slicks' appearance by dispersing it in subsurfaces making the interpretation of optical data non-trivial at all $[5,6]$.

It is internationally recognized that oil spill response operational services obtain great benefits by utilizing airborne/satellite-based remote sensing for oil spill surveillance $[9,10]$. In fact, several countries and governmental agencies, e.g. the European Maritime Safety Agency, assist their operational services by providing remotely sensed measurements, especially by SAR imagery. The latter is an active, coherent, band-limited microwave high-resolution sensor that can make day- and night-time measurements almost independently of atmospheric conditions. Among the currently available SAR systems, the Italian COSMO-SkyMed (CSK) one is attractive from an operational point of view since it is a constellation of four X-band SARs, characterized by a very short revisit time, i. e., $\approx 12$ hours, and it is able to operate in an incoherent dual-polarization mode (Ping Pong, PP, mode). The capability of CSK to support an operational monitoring of the oceans have been demonstrated in [11] - [13].

SAR oil slick observation is physically possible because an oil slick damps the short gravity and capillary waves which are responsible for the backscattering to the SAR antenna and therefore a low backscattering return occurs. As a result, in the SAR image plane, a dark area is associated to an oil slick [14]. SAR oil spill detection is not an easy task, since SAR images are affected by multiplicative noise, known as speckle, which hampers the interpretability of such images. Furthermore, there are other physical phenomena, known as look-alikes, which can generate dark areas in SAR images not related to 
oil spills, such as biogenic films, low-wind areas, rain cells, internal waves and oceanic or atmospheric fronts [15]. Accordingly, tailored filtering techniques must be developed in order to minimize the number of false alarms. They are generally based on the use of single-polarization SAR data together with ancillary data $[5,14,16]$. In some cases, the distinction between oil slicks and biogenic films is based on optical data [5]. The importance of dual co-polarization SAR measurements has been demonstrated in literature for oil slicks observation purposes [17] - [19]. Nevertheless, although it has been physically demonstrated by theoretical modelling and experiments that polarimetric SAR measurements are the most adequate source to monitor oil slicks at sea $[10,20]$, it is important to analyze, especially in the occurrence of large oil spill incidents, how all the available SAR measurements can be exploited at best. In this study a dual co-polarization analysis of the capabilities of X-band CSK PP mode SAR data is first undertaken focusing on the DWH oil spill. The latter was extensively monitored by means of L-, C- and X-band SAR systems but, to the best of our knowledge, no study exploited the incoherent CSK PP mode to consider such a huge oil spill event [21] - [24]. Oil spill detection and estimation of the polluted area is undertaken using a textural-based image processing approach, while a dual co-polarization analysis is undertaken in order to characterize the contrast, i. e., the ratio between the Normalized Radar Cross Section (NRCS) relevant to the slick-free and oil-covered sea surface, both in the $\mathrm{HH}$ and VV channels. In addition, ancillary wind speed information is also extracted from the CSK imaged scene using a spectral method.

Experiments, accomplished over X-band HH-VV PP mode Single-look Complex Slant (SCS) Level 1A CSK SAR data collected in the Gulf of Mexico over the polluted area, demonstrate the importance of the Italian constellation of CSK SAR satellites for an effective observation of sea oil slicks.

\section{The Deepwater Horizon incidental oil spill: a case study}

On 20 April 2010, a fire broke out on the Transocean DWH oil rig under lease to British Petroleum (BP), with 126 people on board (see Figure 1 (a)). After a large explosion, all but 11 of the crew managed to escape as the rig was overwhelmed by fire. On 22 April 2010, the rig sank. Safeguards set in place to automatically cap the oil well in case of catastrophe did not work as expected. According to a first conservative Minerals Management Service formula, BP estimated at worst a spill of 162,000 barrels per day and a standard technology recovery capacity of about 500,000 barrels per day. Only after 12 weeks did BP succeed in placing a tight cap on the well. A first estimate of about 5 million barrels $[25,26]$ already makes this incident the world's largest incidental oil spill and, by far, the worst oil disaster in United States history. It is surpassed only by the intentional 1991 Gulf War spill in Kuwait. Oil spilled from the DWH wellhead was a Mississippi Canyon Block 252 (MS252) South Louisiana sweet, i. e., low in sulfur concentration, crude oil and, as far as for all the crude oils, it consists of thousands of chemical compounds [25,26]. The vast and persistent DWH spill challenged response capabilities which called for quantitative oil assessment at synoptic and operational scales. Although nowadays oil spill response still mainly relies on experienced observers, few trained observers and confounding factors, including weather, oil emulsification and scene illumination geometry presented very non-trivial challenges [27,28]. Moreover, the DWH spill was characterised by some key peculiarities that made its observation very challenging:

- the spill originated from a water-depth of $1500 \mathrm{~m}$. This has confounded many problems on understanding the behaviour of the oil $[29,30]$. In general, oil at sea is influenced by a number of advective processes, e.g. wind and wave advection, spreading, etc., and weathering. The latter is a non-advective process that alters the oil's chemical and physical properties. In addition to the conventional weathering process on the surface, the DWH oil was subjected to weathering as it ascended from the well. In fact, DWH oil appeared to be incorporating water as it emerged on the surface $[29,30]$;

- fresh oil was continuously released. Unlike "conventional" tankers oil spills, where oil is released at once, the DWH oil spill was far more challenging due to continuous fresh oil release. 
(a)

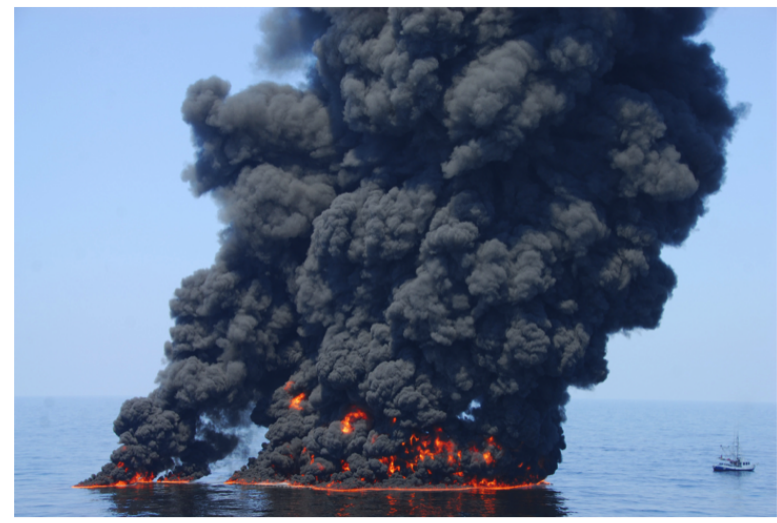

(b)

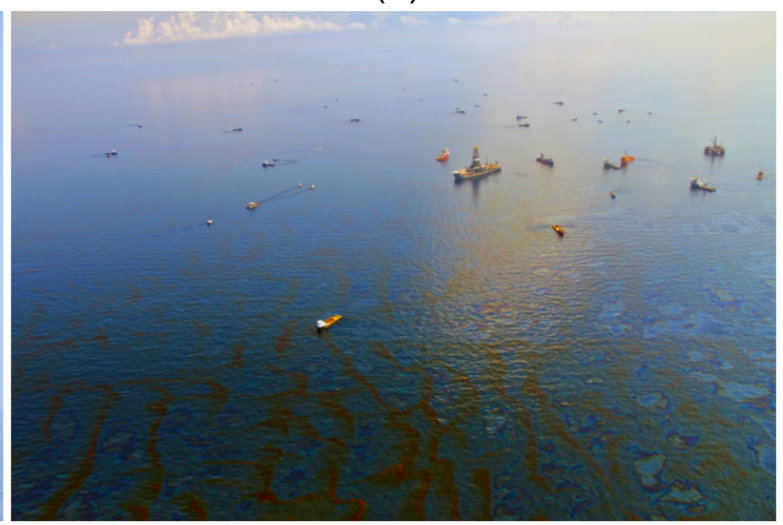

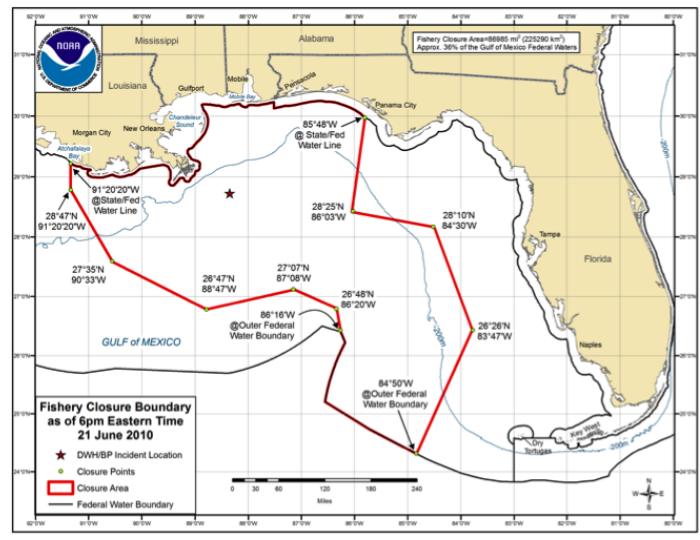

(c)

Figure 1. The DWH oil spill incident. (a) Burning of the BP DWH oil rig; (b) Remediation activities; (c) Fishery closure boundaries 1 day after the incident (courtesy of NOAA).

Hence, in a continuous release situation there is a mixture of fresh and weathered oil (of various degrees) as well as emulsified oil;

- a massive use of dispersants was made to mitigate the oil's impact on the environment $[26,29]$. The dispersants help to reduce the oil-water interfacial tension which, when aided by the addition of energy in the form of wind/waves, can help to enhance natural dispersion of the oil. During the DWH oil spill, nearly 2 million of gallons of chemical dispersant were used both on the surface and directly onto the gushing oil at the wellhead in an attempt to keep some of the oil under the water surface (see Figure 1 (b)). Scientists believe that BP's excessive use of dispersants have contributed significantly to the enormous underwater oil plumes that remain in the Gulf, one of which was 22 miles long and six miles wide [26,29];

- According to the National Oceanic and Atmospheric Agency (NOAA) estimates, the polluted area was so large $\left(10,000 \mathrm{~km}^{2}\right)$ to suggest closing the fishery boundaries (see the area within the red line in Figure 1 (c)) [25]. This hampered traditional approaches to provide a synoptic spill observation, thus making remote sensing a key asset [31].

In addition, such huge oil spillage may have a critical long-term impact over the whole marine and coastal ecosystem and, therefore, still needs to be continuosly monitored [32] - [34].

In summary, this unprecedented oil spill incident triggered the operational use of SAR techniques to provide detailed information on the surfactants related to the DWH incident. Nevertheless, since the DWH polluted area includes oil slicks of different thickness, emulsified oil, weathered 
oil, oil/dispersant mixture, fresh oil, etc., the surface slick is very heterogeneous, including different kind of surfactants. This implies that a synergistic use of different SAR operating modes is needed. In fact, large-swath imaging modes, e. g., ScanSAR, allow obtaining information on the extent of the oil spill, while narrower swath polarimetric modes, e. g., PP, allow extracting deeper information on the oil's backscattering.

\section{Experiments and discussion}

In this section the capability of the CSK PP imaging mode to observe the huge DWH incident in the Gulf of Mexico is demonstrated. The signal backscattered from slick-free and oil-covered sea surface is analyzed using both $\mathrm{HH}$ and VV channels and a wind speed map, derived from the CSK imagery, is used to assess that moderate wind conditions applied when the scene was imaged by CSK. The proposed methodology is synthetically described in Figure 2 where a flowchart is shown.

The CSK SAR data set consists of a multi-polarization SAR scene collected in right-looking ascending orbit over the DWH incidental oil spill site in the very next days after the incident, see Figure 3 . The SAR scene (product ID: 2006020) was acquired from the satellite " 3 " of the constellation on April 23, 2010, i. e., only 3 days after the oil spillage just after the BP oil rig sank, in dual co-polarization, i. e., $\mathrm{HH}-\mathrm{VV}$, PingPong mode under an incidence angle of $40^{\circ}$ at mid-range. The SAR image consists of $4123 \times 18042$ pixels covering an area of $30 \mathrm{~km} \times 30 \mathrm{~km}$ with about $15 \mathrm{~m}$ spatial resolution.

A key parameter when observing sea oil slicks by SAR imagery is sea surface wind speed. In fact, it is unanimously recognized that SAR oil slick observation is possible when moderate wind conditions, i. e., wind speed ranges from about $2 \mathrm{~m} / \mathrm{s}$ up to approximately $13 \mathrm{~m} / \mathrm{s}[9,35]$. When higher wind conditions apply, the mixing phenomena resulting from high sea state significantly hamper the detectability of the surfactant with respect to the surrounding sea. At lower wind speeds, sea surface backscattering is comparable to the scattering from the oil slick; in this case, the oil spill detection performance from SAR imagery becomes poorer due to the false alarms associated to low-backscattering areas. Typically, wind information over sea surface is provided by ancillary in-situ and/or remotely sensed data, e. g., buoy measurements and/or scatterometer and radiometer satellite data. The former measure sea surface wind speed at the usual height of $5 \mathrm{~m}$, while the latter allow retrieving sea surface wind speed at a reference height of $10 \mathrm{~m}$ above sea level [36] - [38]. Unfortunately, very often the information coming from other remotely sensed sources is not co-located in time and/or space with the available SAR data set. In addition, buoys co-located to the incident point are not always available.

Hence, in this study, a different approach is proposed that consists of deriving the sea surface wind speed map, at the standard height of $10 \mathrm{~m}$, from the SAR image. This means that time- and space-colocated wind information is extracted. Different methods are available in literature that are mainly based on the exploitation of a scatterometer-like Geophsyical Model Function (GMF) to extract wind speed information once a priori wind direction information is available [36] - [38]. In this study, a spectral approach is considered that does not require any a priori wind direction information to provide the sea surface wind speed map. This approach is based on the inherent SAR peculiarities, i. e., the low-pass filtering in the azimuth direction due to the orbital motion of the sea surface waves that distorts the Doppler history of the backscattered waves $[39,40]$. The wind map, generated using the azimuth cut-off method, is shown in Figure 4 (a), where the oil-covered area is masked out. It can be noted that low-to-moderate wind regime applies that is characterized by a mean wind speed of $7 \mathrm{~m} / \mathrm{s}$ at the SAR acquisition time. This result agrees with the sea surface wind speed derived from the Oceansat-2 (OSCAT) level 2B $12.5 \mathrm{~km}$ spatial resolution scatterometer product available from the National Aeronautics and Space Administration (NASA) Jet Propulsion Laboratory (JPL) database [41], whose wind speed map is shown in Figure 4 (b). SAR-derived wind speed is also confirmed by the $5 \mathrm{~m}$-sea surface wind speed recorded at the SAR acquisition time by the available NOAA buoy closest to the DWH incident site, i. e., the station ID “42040" (located at $29^{\circ} 12^{\prime} 30^{\prime \prime} \mathrm{N}, 88^{\circ} 13^{\prime} 3^{\prime \prime}$ W, about $50 \mathrm{~km}$ far along north-east direction, [42]) and corrected for a fair comparison with SAR-based wind speed retrieval $[37,38]$. Hence, CSK imagery can be successfully exploited to retrieve a key ancillary 


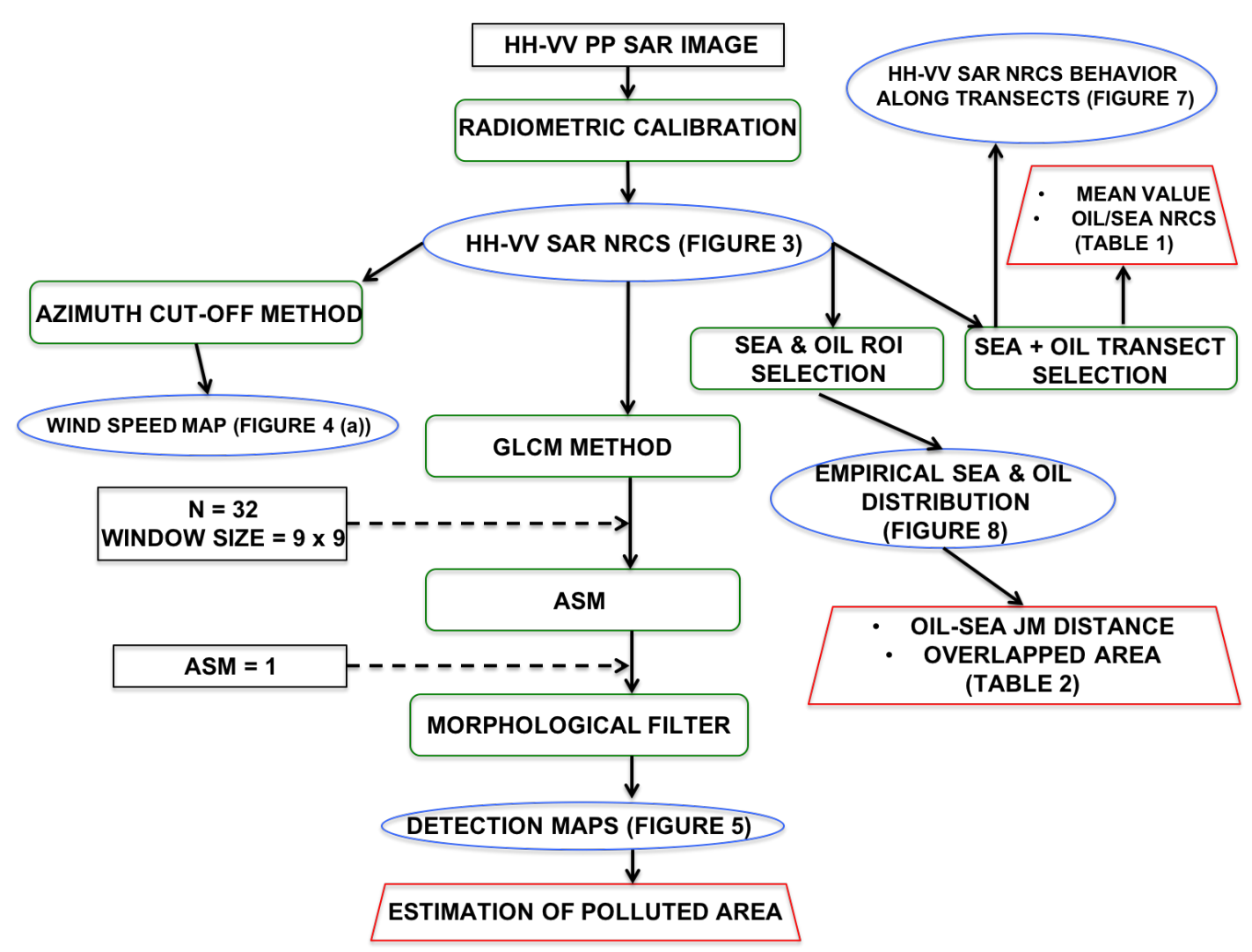

Figure 2. Flowchart of the proposed methodology. Black boxes refer to input data/parameters, green boxes refer to processing steps, blue boxes refer to output maps/plots shown as figures and red boxes refer to output values listed in tables.

information related to sea oil slick observation, namely sea surface wind speed. Once this ancillary information states that low-to-moderate wind regime applies, the detection problem can be tackled.

\subsection{Oil spill detection}

In this subsection a texture-based oil spill detection procedure is undertaken to assess the potential of CSK SAR data to detect the DWH oil spill and to estimate its surface extent.

In order to extract suitable intensity-based features that allow obtaining the oil spill detection binary mask, a textural-based feature extraction algorithm is adopted using the Gray-Level Co-occurrence Matrix (GLCM). The latter is one of the most popular statistical method to extract second-order texture features from remotely sensed images. The technique has been already successfully exploited in a broad range of SAR applications, e. g., ice-cover classification [43] and oil detection [44]. Basically, GLCM is a mathematical formalism that takes into account how often different pixel intensity value combinations occur in a remotely sensed image within given distances and directions. Among the basic GLCM parameters that can be extracted from a SAR image, which include mean, variance, correlation, entropy, homogeneity, energy, contrast, dissimilarity, etc., the Angular Second Moment (ASM) was found to be the most effective in separating the oil-covered area from the surrounding sea. ASM is defined as:

$$
\sum_{i, j=0}^{N}[I(i, j)]^{2},
$$

where $I$ is the original intensity SAR image and $N$ is the number of gray levels [45]. ASM can be seen as a measure of homogeneity of the intensity SAR image. Since the oil-covered area is expected to be more 


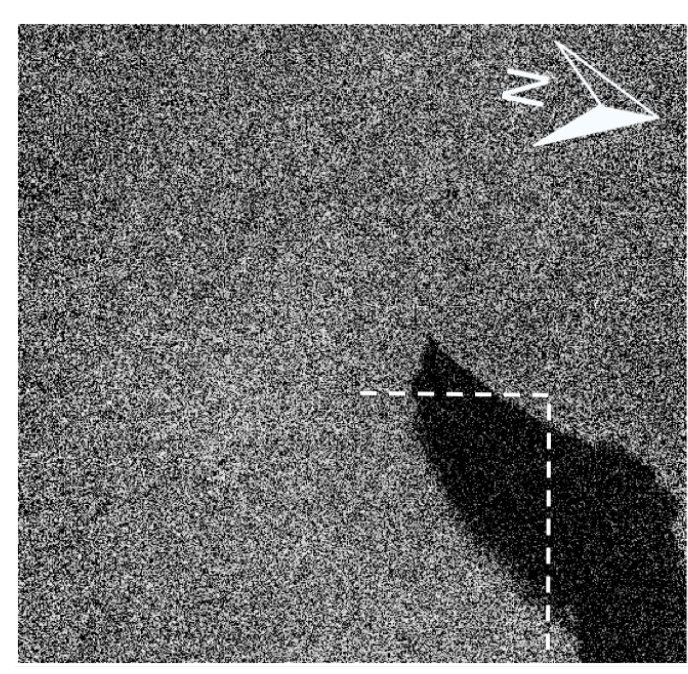

(a)

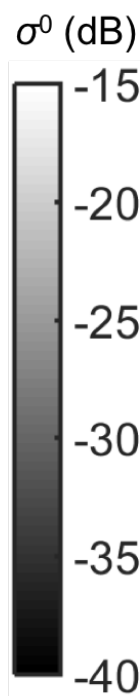

$-40$

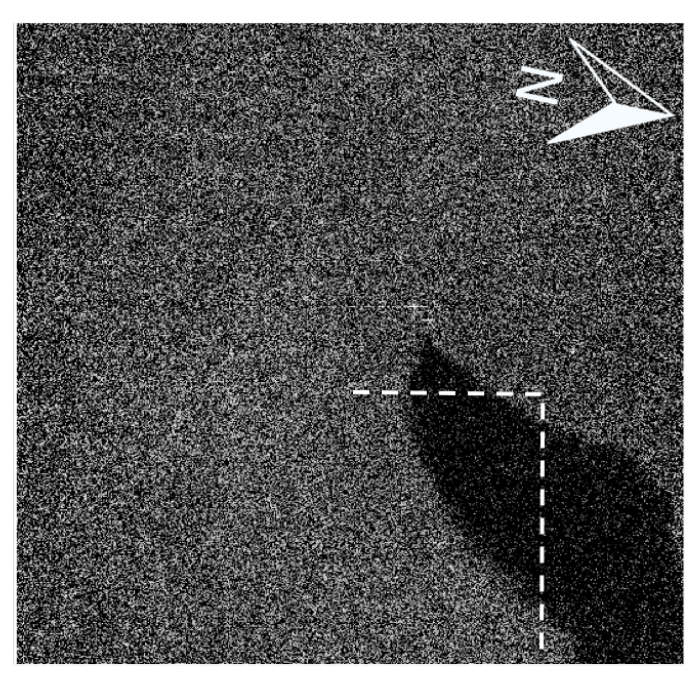

(b)

Figure 3. Dual co-polarization CSK SAR imagery related to the SAR scene collected on 23 April 2010. (a) HH- and (b) VV-polarized NRCS graytone images (dB scale). The area polluted by the DWH incident is visible as a homogeneous patch darker than the sea background. The along-range and along-azimuth transects are also annotated as dashed white lines.

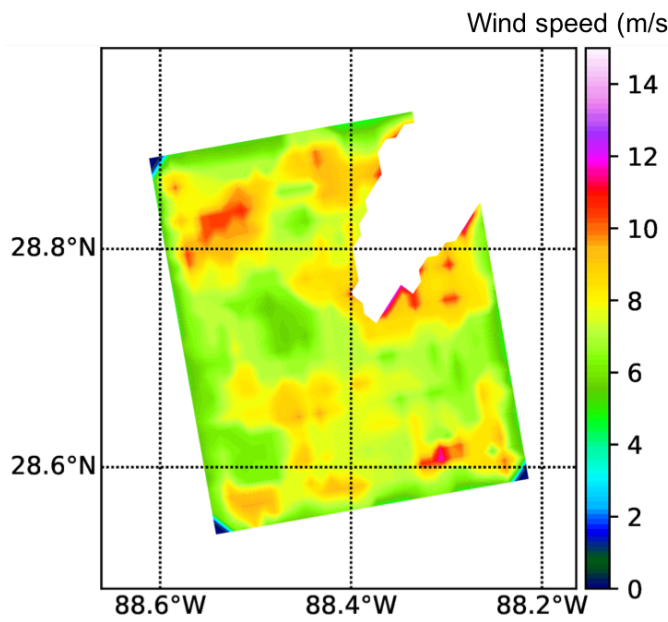

(a)

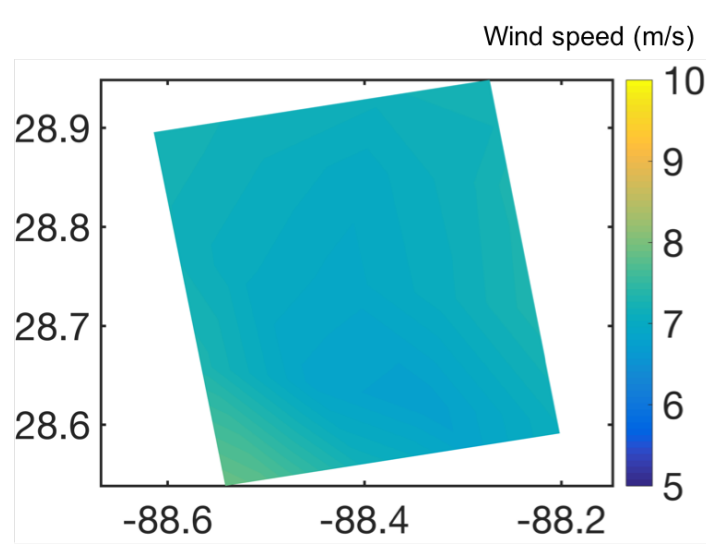

(b)

Figure 4. Wind speed map obtained from: (a) azimuth cut-off algorithm applied on the CSK SAR scene collected on 23 April 2010; (b) OSCAT level 2B scatterometer measurement. 


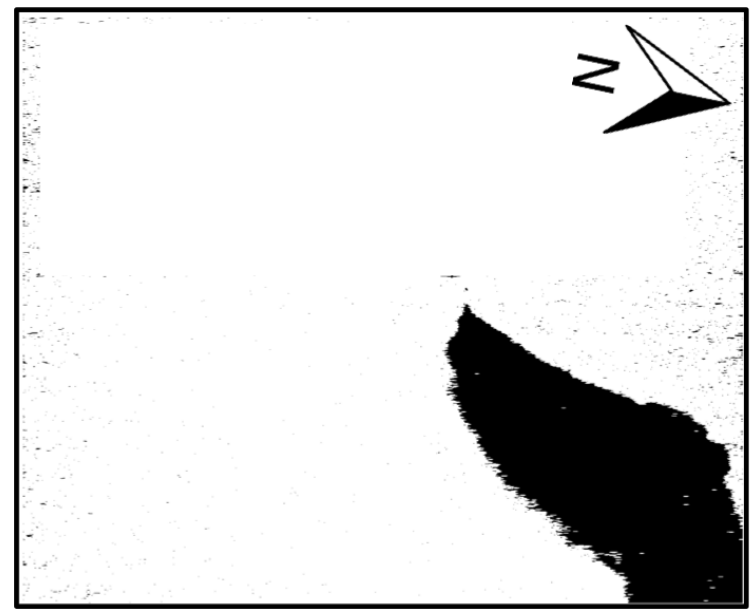

(a)

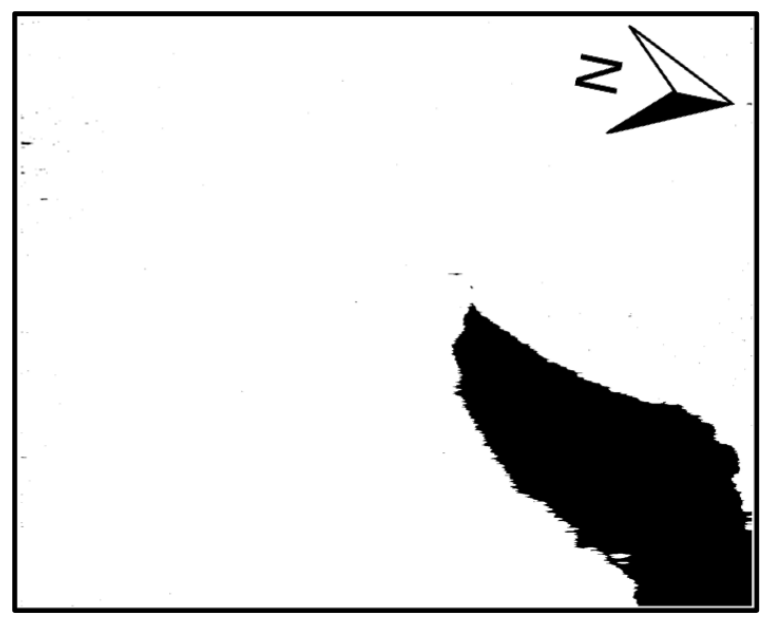

(b)

Figure 5. ASM-based oil detection maps relevant to the CSK SAR scene collected on 23 April 2010. (a) $\mathrm{HH}$ and (b) VV channel.

homogeneous than the sea surface, i. e., few gray levels are present, it will be characterized by few and relatively high intensity values $I(i, j)$ that result in ASM values larger than the ones characterizing sea surface. According to [46], the number of gray levels should be neither too small nor too large in order to reduce the loss of information due to quantization process and to preserve the amount of textural details, while the sliding window size should be neither too small nor too large in order to consider sufficient texture information and to reduce the "block/pixelation" effect without avoiding excessive time consuming processing. Hence, in this study, quantization in $N=32$ gray levels and a 9 $\times 9$ sliding window are used to estimate ASM.

Oil spill detection results are shown in Figure 5, where the binary masks obtained thresholding the ASM images are obtained from HH and VV channel (see Figure 5 (a) and (b), respectively). A threshold $\mathrm{ASM}=1$ is empirically set. Post-processing techniques, e. g., a morphological filter, is then applied to derive the oil detection maps of Figure 5. It can be noted that the oil detection mask obtained from the VV NRCS clearly separates the polluted area, that calls for ASM values larger than 1 due to its homogeneity, from the surrounding sea, that represents a more heterogeneous scenarios resulting in a lower ASM values (see Figure 5 (b)). It is also important to note that the few isolated black spots related to metallic targets at sea involved in cleaning-up operations (see bright spots in Figure 3) are visible in the oil spill detection map. This is likely due to the fact that they behave as very homogeneous scatterers. The oil spill can be detected even from the HH NRCS, although a very slightly larger number of false alarms and missed oil pixels within the slick are observed, see Figure 5 (a).

Hence, according to the detection map of Figure 5 (b), the extent of the DWH oil spill can be estimated to be approximately $100 \mathrm{~km}^{2}$ at the SAR acquisition time, i. e., 3 days after the incident.

\subsection{Dual co-polarization analysis}

In this subsection the inherent peculiarity of the CSK PP mode, i. e., the capability to incoherently collect images at $\mathrm{HH}$ and $\mathrm{VV}$ polarization, is exploited and the sensitivity of $\mathrm{HH}$ - and VV-polarized NRCS, $\sigma_{H H}^{0}$ and $\sigma_{V V}^{0}$, respectively, to slick-free and oil-covered backscattering, is discussed.

The two intensity channels are jointly used to generate the Pauli false-color RGB images of Figure 6 where the following color-coding is adopted: $\mathrm{R}\left(\sigma_{V V}^{0}\right) ; \mathrm{G}\left(\sigma_{H H}^{0}\right)$ and $\mathrm{B}\left(\sigma_{H H}^{0}-\sigma_{V V}^{0}\right)$. It can be noted that the joint use of $\mathrm{VV}$ and $\mathrm{HH}$ channels provides further information that can be exploited to gain a better understanding of the scattering processes. The backscattering from metallic targets (mostly due to ships and oil/gas drilling platforms), see brighter spots in Figure 3, is significantly larger than the sea one at both $\mathrm{HH}$ and VV polarizations. Sea surface backscattering results in VV-polarized 
Table 1. Dual co-polarization analysis results.

\begin{tabular}{cccccc}
\hline \hline Transect & ROI & $\sigma_{V V}^{0}(\mathrm{~dB})$ & $\sigma_{H H}^{0}(\mathrm{~dB})$ & $\Delta_{V V}(\mathrm{~dB})$ & $\Delta_{H H}(\mathrm{~dB})$ \\
\hline \multirow{2}{*}{$\begin{array}{c}\text { Azimuth } \\
\text { Direction }\end{array}$} & Sea & -24.13 & -27.34 & 12.43 & 10.53 \\
\cline { 2 - 4 } & Oil & -36.59 & -37.86 & & \\
\hline \hline & & & & & \\
Range & Sea & -22.62 & -25.85 & \multirow{2}{*}{14.40} & 12.11 \\
\cline { 2 - 4 } Direction & & & & & \\
\cline { 2 - 5 } & Oil & -37.00 & -37.96 & & \\
\hline \hline
\end{tabular}

backscattering larger than the oil-covered area, as expected from the Bragg/tilted-Bragg theory [47]. The smallest difference between VV- and HH-polarized backscattering is achieved within the oil-covered areas. From a physical viewpoint, this can be explained considering that oil layer reduces significantly Bragg scattering waves leading to a noise-like backscattering which results in practically no difference between $\mathrm{HH}$ and VV channels.

To provide a quantitative analysis of $\mathrm{VV}$ and $\mathrm{HH}$ backscattering over slick-free and oil-covered sea surface, $\sigma_{V V}^{0}$ and $\sigma_{H H}^{0}$ values related to the azimuth- and range-oriented transects, see white dashed lines in Figure 3, are depicted in Figure 7. Values related to the along-range transect are depicted in Figure 7 (a), where one can not that: over slick-free sea surface $\sigma_{V V}^{0}>\sigma_{H H}^{0}$ (the difference is about $3 \mathrm{~dB}$ ) since Bragg scattering applies; within the oil-affected area, the backscattering is significantly lower than the sea one and there is negligible difference between HH and VV channels (the difference is less than $1 \mathrm{~dB}$ ). Same comments apply for the azimuth-oriented transect, see Figure 7 (b). The mean values related to slick-free and oil-covered $\sigma^{0}$ values evaluated along with this transect are listed in Table 1 where the contrast $\Delta$, i. e., the slick-free to oil-covered $\sigma^{0}$ ratio, is also listed for both the channels. As expected, the VV-polarized contrast is larger than the $\mathrm{HH}$ one (of about $2 \mathrm{~dB}$ ) due to the larger sea surface backscattering in VV channel.

To further discuss oil-sea separability at both $\mathrm{HH}$ and VV channels, a tailored analysis is made that consists of considering two equal-size Region of Interest (ROIs) kept within the oil-affected area and the slick-free sea surface. The empirical probability density function (pdf) related to slick-free and oil-covered $\sigma^{0}$ values (in $\mathrm{dB}$ ) are shown for both the VV and HH channels, see Figure 8. It can be noted that there is a good oil-sea separability at both $\mathrm{HH}$ and VV polarization according to the Jeffries-Matusita (JM) distance, see Table 2. The JM distance is defined as:

$$
J M=2\left(1-e^{-B}\right) \quad, \quad B=-\ln \left(\sum_{x \in X} \sqrt{(p(x) q(x)}\right),
$$

where $B$ is the Bhattacharyya distance between the distribution pixel $x$ belonging to slick-free $(p)$ and oil-covered $(q)$ ROIs [48]. In fact, the minimum $J M$ value, i. e., 0 , means that the two distribution are completely overlapped while the maximum $J M$ value, i. e., 2, means totally separated distributions. Results listed in Table 2 clearly show that the largest oil-sea separation is provided by VV channel (JM $=1.0763$ ) with a $40 \%$ overlapping between oil and sea pdfs. However, even the HH channel performs fine in oil-sea separation ( $J M=0.8232)$ with an overlapping equal to $50 \%$. It can be also observed that the largest separation is provided by the combination of $\sigma_{H H}^{0}$ evaluated over oil and $\sigma_{V V}^{0}$ evaluated over slick-free sea surface. 


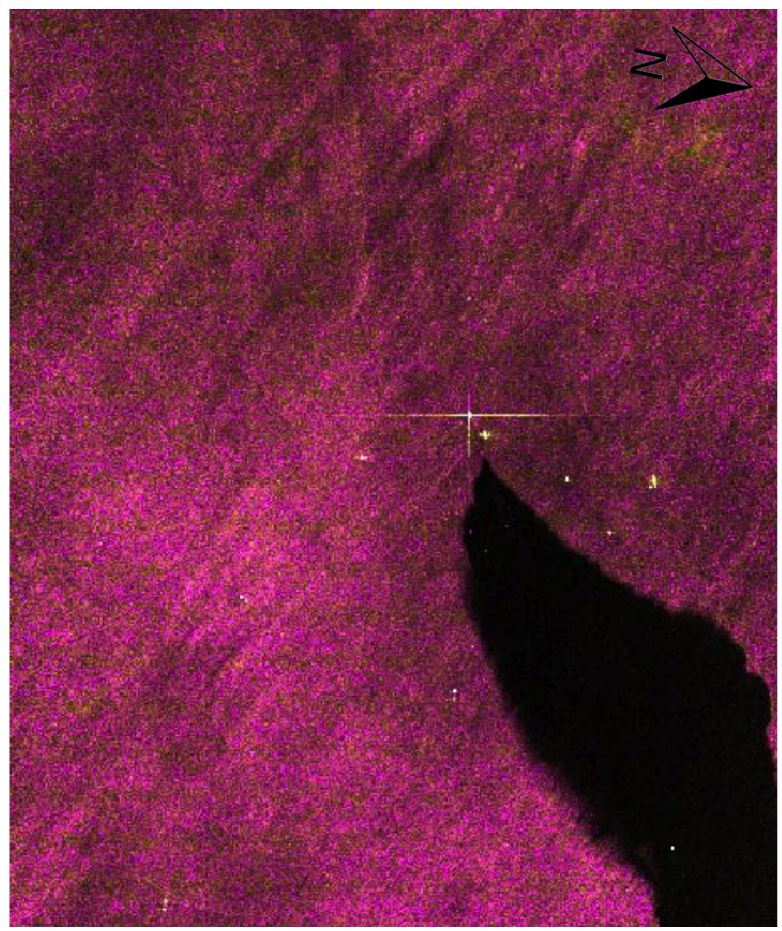

Figure 6. False-color RGB image relevant to the CSK SAR scene collected on 23 April 2010, where the following color-coding is adopted: $\mathrm{R} \equiv \sigma_{V V}^{0}, \mathrm{G} \equiv \sigma_{H H}^{0}$ and $\mathrm{B} \equiv \sigma_{H H}^{0}-\sigma_{V V}^{0}$.

(a)

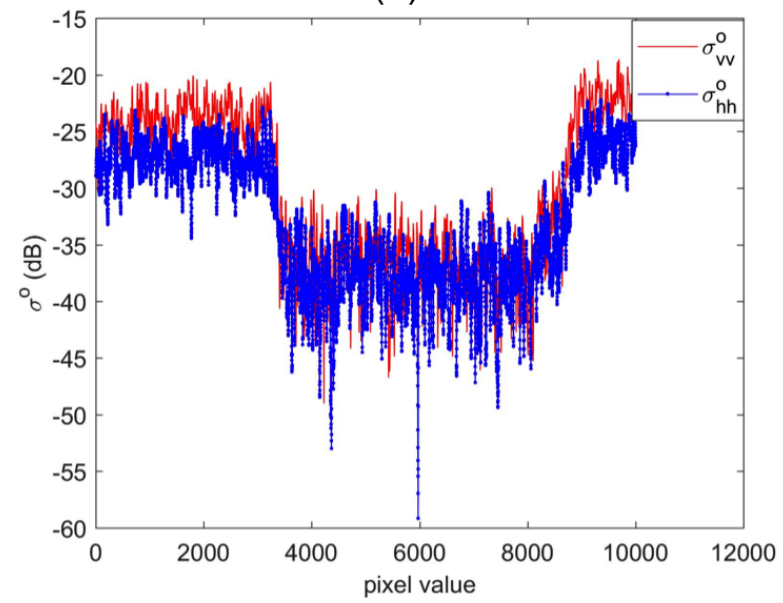

(b)

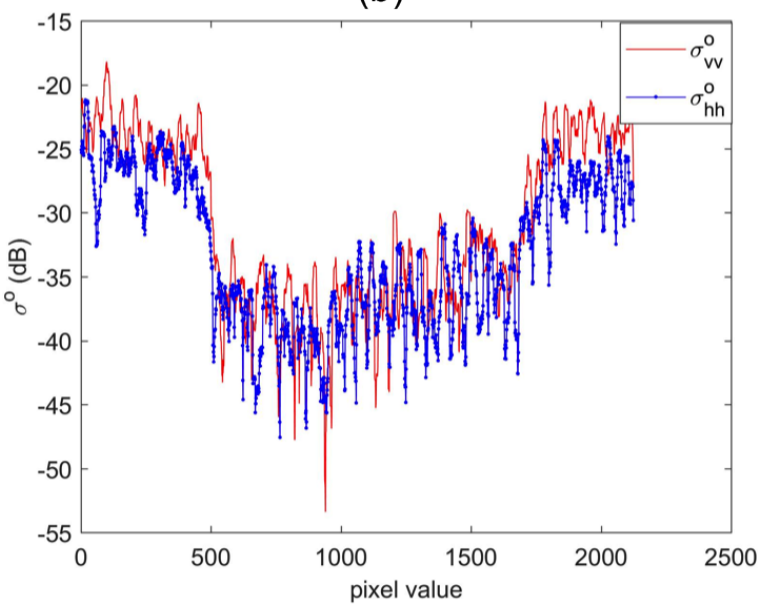

Figure 7. HH- and VV-polarized NRCS values (in $\mathrm{dB}$ ) evaluated along with the range- (a) and azimuth-oriented (b) transects shown in Figure 3.

Table 2. Statistical oil-sea separability.

\begin{tabular}{ccc}
\hline \hline Parameter & HH & VV \\
\hline Oil-sea $J M$ & 0.8232 & 1.0763 \\
\hline Overlapped area $(\%)$ & 50 & 40 \\
\hline \hline
\end{tabular}




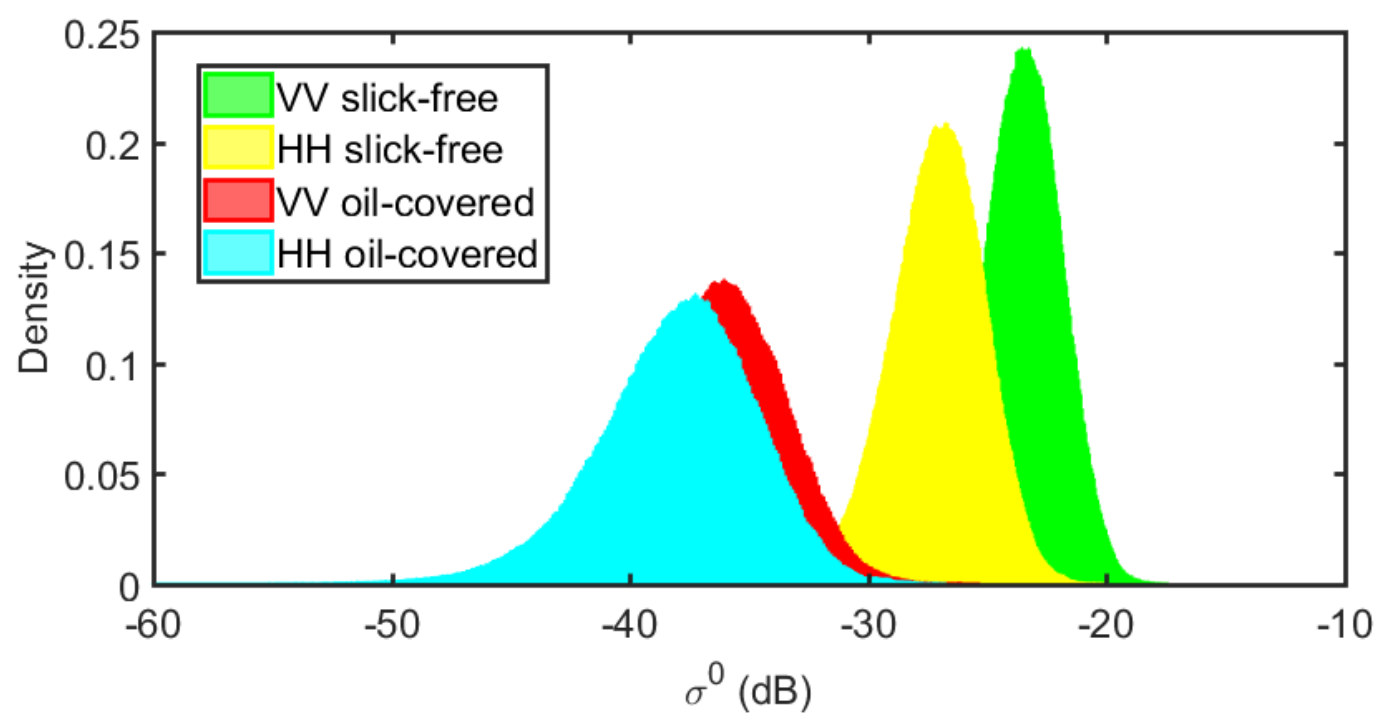

Figure 8. Empirical pdfs related to $\sigma^{0}$ values evaluated over the slick-free and oil-covered sea surface ROIs for both the VV and $\mathrm{HH}$ channels.

\section{Conclusions}

In a general operational view, this study is a tile in a larger mosaic where the most reliable tiles are based on physical processing, i. e., use of coherent polarimetric SAR measurements along with appropriate modelling [10], [17-19], [23], but where less reliable tiles can be also exploited.

In this study the high-performance CSK imagery capabilities are exploited to observe a huge oil spill incident, namely the Deepwater Horizon oil slick, occurred in 2010 in the Gulf of Mexico, off the Louisiana coast. The CSK dual co-polarization incoherent mode is shown to be a key tool to support local authorities since it provides: a) a binary image where the oil-affected sea can be easily identified; b) sea surface wind speed information whose availability helps to make SAR-based sea oil spill observation effective and reliable.

The analysis of the signal backscattered off an oil-free and oil-covered sea surface shows that, as expected, sea surface VV-polarized backscattering is larger than the HH one. However, this difference turns out to be negligible when oil-covered backscattering is considered.

Acknowledgments: This study is partly funded by the Università degli Studi di Napoli Parthenope, project ID DING202. We thank the Italian Space Agency (ASI) that has provided the CSK SAR data under the project ID 1221. Authors would also acknowledge ASI and E-Geos for useful discussions.

Author Contributions: Ferdinando Nunziata and Maurizio Migliaccio conceived and designed the experiments; Andrea Buono and Ferdinando Nunziata performed the experiments and analyzed the data; Ferdinando Nunziata, Andrea Buono and Maurizio Migliaccio wrote the paper.

Conflicts of Interest: The authors declare no conflict of interest. The founding sponsors had no role in the design of the study; in the collection, analyses, or interpretation of data; in the writing of the manuscript, and in the decision to publish the results.

\section{Abbreviations}

The following abbreviations are used in this manuscript: 


$\begin{array}{ll}\text { SAR } & \text { Synthetic Aperture Radar } \\ \text { DWH } & \text { DeepWater Horizon } \\ \text { CSK } & \text { COSMO-SkyMed } \\ \text { HH } & \text { Horizontal transmit Horizontal receive } \\ \text { VV } & \text { Vertical transmit Vertical receive } \\ \text { PP } & \text { PingPong } \\ \text { NRCS } & \text { Normalized Radar Cross-Section } \\ \text { SCS } & \text { Single-look Complex Slant } \\ \text { BP } & \text { British Petroleum } \\ \text { NOAA } & \text { National Oceanic and Atmospheric Agency } \\ \text { GMF } & \text { Geophsyical Model Function } \\ \text { OSCAT } & \text { Oceansat-2 } \\ \text { NASA } & \text { National Aeronautics and Space Administration } \\ \text { JPL } & \text { Jet Propulsion Laboratory } \\ \text { dB } & \text { Decibel } \\ \text { GLCM } & \text { Gray-Level Co-occurrence Matrix } \\ \text { ASM } & \text { Angular Second Moment } \\ \text { RGB } & \text { Red Green Blue } \\ \text { ROI } & \text { Region Of Interest } \\ \text { pdf } & \text { Probability Density Function } \\ \text { JM } & \text { Jeffries-Matusita } \\ \text { ASI } & \text { Italian Space Agency }\end{array}$

\section{References}

1. Costanza, R. The ecological, economic, and social importance of the oceans. Ecol. Enon. 1999, 31, 199-213.

2. Visbeck, M. Ocean science research is key for a sustainable future. Nat. Comm. 2018, 9, 1-4.

3. Fanning, L.; Mahon, R.; Baldwin, K.; Douglas, S. Transboundary Large Marine Ecosystems. In Transboundary Waters Assessment Programme (TWAP) Assessment of Governance Arrangements for the Ocean; Intergovernmental Oceanographic Commission Technical Series 119, United Nations Educational, Scientific and Cultural Organization; Paris, France, 2015.

4. United Nations. The Sustainable Development Goals Report 2016. United Nations; New York, USA, 2016.

5. Fingas, M.; Brown, C. E. Review of Oil Spill Remote Sensing. Spill Sci. Technol. Bull. 1997, 4, 199-208.

6. Fingas, M.; Brown, C. E. Oil Spill Remote Sensing. In Handbook of Oil Spill Science and Technology; Fingas, M., Eds.; Wiley, 2015; 313-356, 978-0-470-45551-7.

7. Leifer, I.; Lehr, W. J.; Simecek-Beatty, D.; Bradley, E.; Clark, R.; Dennison, P.; Hu, Y.; Matheson, S.; Jones, C. E.; Holt, B.; Reif, M.; Roberts, D. A.; Svejkovsky, J.; Swayze, G.; Wozencraft, J. State of the art satellite and airborne marine oil spill remote sensing: Application to the BP oil spill. Remote Sens. Environ. 2012, 124, 185-209.

8. Beyer, J., Trannum, H. C.; Bakke, T.; Hodson, P. V.; Collier, T. K. Environmental effects of the Deepwater Horizon oil spill: A review. Mar. Poll. Bullet. 2016, 110, 28-51.

9. Solberg, A. H. S. Remote Sensing of Ocean Oil Spill Pollution. Proc. IEEE 2012, 10, 2931-2945.

10. Migliaccio, M.; Nunziata, F.; Buono, A. SAR polarimetry for sea oil slick observation. Int. J. Remote Sens. 2015, 36, 3243-3273.

11. Dietrich, J. C.; Trahan, C. J.; Howard, M. T.; Fleming, J. G.; Weaver, R. J.; Tanaka S.; Yu, L.; Luettich Jr., R. A.; Dawson, C. N.; Westerink, J. J.; Wells, G.; Lu, A.; Vega, K.; Kubach, A.; Dresback, K. M.; Kolar, R. L.; Kaiser, C.; Twilley, R. R. Surface trajectories of oil transport along the Northern Coastline of the Gulf of Mexico. Cont. Shelf. Res. 2012, 41, 17-47.

12. Cheng, Y.; Liu, B.; Li, X.; Nunziata, F.; Xue, Q.; Ding, X.; Migliaccio, M.; Pichel, W. G. Monitoring of oil spill trajectories with COSMO-SkyMed X-band SAR images and model simulation. IEEE J. Sel. Topics in Appl. Earth Obs. Remote Sens. 2014, 7, 2895-2901.

13. Montuori, A.; Nunziata, F.; Migliaccio, M.; Sobieski, P. X-band two-scale sea surface scattering model to predict the contrast due to an oil slick. IEEE J. Sel. Topics in Appl. Earth Obs. Remote Sens. 2016, 13, 4970-4978. 
14. Brekke, C.; Solberg, A. H. S. Oil spill detection by satellite remote sensing. Remote Sens. Environ. 2005, 95, 1-13.

15. Gade, M.; Alpers, W.; Huhnerfuss, H.; Masuko, H.; Kobayashi, T. Imaging of Biogenic and Anthropogenic Ocean Surface Films by the Multifrequency/Multipolarization SIR-C/X-SAR. J. Geophys. Res. 1998, 103, 18851-18866.

16. Wismann, V.; Gade, M.; Alpers, W.; Huhnerfuss, H. Radar signatures of marine mineral oil spills measured by an airborne multi-frequency radar. Int. J. Remote Sens. 1998, 19, 3607-3623.

17. Nunziata, F.; Gambardella, A.; Migliaccio, M. On the Mueller Scattering Matrix for SAR Sea Oil Slick Observation. IEEE Geosci. Remote Sens. Lett. 2008, 5, 691-965.

18. Migliaccio, M.; Nunziata, F.; Gambardella, A. On the Co-polarised Phase Difference for Oil Spill Observation. Int. J. Remote Sens. 2009, 30, 1587-1602.

19. Velotto, D.; Migliaccio, M.; Nunziata, F.; Lehner, S. Dual-polarized TerraSAR-X Data for Oil Spill Observation. IEEE Trans. Geosci. Remote Sens. 2011, 30, 1587-1602.

20. Gambardella, A.; Giacinto, G.; Migliaccio, M.; Montali, A. One-class classification for oil spill detection. Pattern Anal. Applic. 2010, 13, 349-366.

21. Jones, C. E.; Minchew, B.; Holt, B.; Hensley, S. Studies of the Deepwater Horizon Oil Spill with the UAVSAR Radar. In Monitoring and Modeling the Deepwater Horizon Oil Spill: A Record-Breaking Enterprise, Geophysical Monograph Series 195; American Geophysical Union, Washington D.C., 2011; 33-50.

22. Minchew, B.; Jones, C. E.; Holt, B. Polarimetric Analysis of Backscatter from Deepwater Horizon Oil Spill Using L-band Synthetic Aperture Radar. IEEE Trans. Geosci. Remote Sens. 2012, 50, 1-19.

23. Migliaccio, M.; Nunziata, F. On the Exploitation of Polarimetric SAR Data to Map Damping Properties of the Deepwater Horizon Oil Spill. Int. J. Remote Sens. 2014, 35, 3499-3519.

24. Garcia-Pineda, O.; Holmes, J.; Rissing, M.; Jones, R.; Wobus, C.; Svejkovsky, J.; Hess, M. Detection of Oil near Shorelines during the Deepwater Horizon Oil Spill Using Synthetic Aperture Radar (SAR). Remote Sens. 2017, 9, 567-586.

25. National Oceanographic and Atmospheric Administration Office of Response and Restoration. Deepwater Horizon Oil: Characteristics and Concerns. Available online: http://docs.lib.noaa.gov/noaa_documents/DWH_IR/reports/OilCharacteristics.pdf

26. National Commission on the BP Deepwater Horizon Oil Spill and Offshore Drilling. Final Report to the President: The Gulf Oil Disaster and the Future of Offshore Drilling. Available online: http:// www.oilspillcommission.gov/final-report.

27. Liu, Y.; Macfadyen, A.; Ji, Z.-G., Weisberg, R. H. Monitoring and Modeling the Deepwater Horizon Oil Spill: A Record-Breaking Enterprise. Geophys. Monogr. Ser. 2011, 195. American Geophysical Union, Washington D.C.; 271.

28. Nunziata, F.; Migliaccio, M. International Oil Spill Response Technical Seminar: Oil Spill Monitoring and Damage Assessment via PolSAR Measurements. Aquat. Procedia 2014, 1-8. Available online: www.sciencedirect.com.

29. National Oceanic and Atmospheric Administration. Natural Resource Damage Assessment: Status Update for the Deepwater Horizon Oil Spill. Available online: http:/ /www.gulfspillrestoration.noaa.gov.

30. Yapa, P. D.; Wimalaratne, M. R.; Dissanayake, A. L.; DeGraff Jr., A. How Does Oil and Gas Behave When Released in Deepwater?. J. Hydro-Environ. Res. 2012, 6, 275-285.

31. Ivshina, I. B.; Kuyukina, M. S.; Krivoruchko, A. V.; Elkin, A. A.; Makarov, S. O.; Cunningham, C. J.; Peshkur, T. A.; Atlas, R. M.; Philp, J. C. Oil spill problems and sustainable response strategies through new technologies. Environ. Sci.-Proc. Imp. 2015, 17, 1211-1209.

32. Vilcaez, J.; Li, L.; Hubbard, S. S. A new model for the biodegradation kinetics of oil droplets: application to the Deepwater Horizon oil spill in the Gulf of Mexico. Geochem. Trans. 2013, 14, 1-14.

33. Valentine, D. L.; Fisher, G. B.; Bagby, S. C.; Nelson, R. K.; Reddy, C. M.; Sylva, S. P.; Woo, M. A. Fallout Plume of Submerged Oil from Deepwater Horizon. P. Natl. Acad. Sci. USA 2014, 111, 15906-15911.

34. Streett, D. D. NOAA'S Satellite Monitoring Of Marine Oil. In Monitoring and Modeling the Deepwater Horizon Oil Spill: A Record-Breaking Enterprise, Geophys. Monogr. Ser. 195; American Geophysical Union, Washington D.C., 2011, 13-91.

35. Alpers, W.; Holt, B.; Zeng, K. Oil spill detection by imaging radars: Challenges and pitfalls. Remote Sens. Environ. 2017, 201, 133-147. 
36. Zhang, B.; Perrie, W.; Vachon, P. W.; Li, X.; Pichel, W. G.; Guo, J.; He, Y. Ocean Vector Winds Retrieval From C-Band Fully Polarimetric SAR Measurements. IEEE Trans. Geosci. Remote Sens. 2012, 50, 4252-4261.

37. Li, X.-M.; Lehner, S. Algorithm for Sea Surface Wind Retrieval From TerraSAR-X and TanDEM-X Data. IEEE Trans. Geosci. Remote Sens. 2014, 52, 2928-2939.

38. Ren, Y.; Li, X.-M.; Zhou, G. Sea Surface Wind Retrievals from SIR-C/X-SAR Data: A Revisit. Remote Sens. 2015, 7, 3548-3564.

39. Stopa, J. E.; Ardhuin, F.; Chapron, B.; Collard, F. Estimating wave orbital velocity through the azimuth cutoff from space-borne satellites. J. Geophys. Res. 2015, 120, 7616-7634.

40. Grieco, G.; Lin, W.; Migliaccio, M.; Nirchio, F.; Portabella, M. Dependency of the Sentinel-1 azimuth wavelength cut-off on significant wave height and wind speed. Int. J. Remote Sens. 2016, 37, 5086-5104.

41. NASA JPL. Physical Oceanography Distributed Active Archive Center. Available online: https://podaac.jpl.nasa.gov/dataset/OS2_OSCAT_LEVEL_2B_OWV_COMP_12_V2.

42. National Oceanic and Atmospheric Administration. National Data Buou Center. Available online: https://www.ndbc.noaa.gov/.

43. Ressel, R.; Frost, A.; Lehner, S. A Neural Network-Based Classification for Sea Ice Types on X-Band SAR Images. IEEE J. Sel. Topics in Appl. Earth Obs. Remote Sens. 2015, 8, 3672-3680.

44. Singha, S.; Vespe, M.; Trieschmann, O.; Automatic Synthetic Aperture Radar based oil spill detection and performance estimation via a semi-automatic operational service benchmark. Mar. Poll. Bullet. 2013, 73, 199-209.

45. Haralick, R. M.; Shanmugam, K.; Dinstein, I. Textural Features for Image Classification. IEEE Trans. Syst., Man, Cybern. 1973, 6, 610-621.

46. Soh, L.-K.; Tsatsoulis, C. Texture Analysis of SAR Sea Ice Imagery Using Gray Level Co-Occurrence Matrices. IEEE Trans. Geosci. Remote Sens. 1999, 37, 780-795.

47. Valenzuela, G. R. Scattering of Electromagnetic Waves from the Ocean. In Surveillance of Environmental Pollution and Resources by Electromagnetic Waves, NATO Advanced Study Institutes Series (Series C Mathematical and Physical Sciences), Springer, Dordrecht. 1978, 45, 199-226.

48. Swain, P. H.; Davis, S. M. Remote Sensing. The Quantitative Approach. McGraw-Hill, New York, USA, 1978. 